\title{
Models for predicting friction coefficient and parameters with influence in elastohydrodynamic lubrication
}

\author{
P Lafont Morgado, J Echávarri Otero*, J B Sánchez-Peñuela Lejarraga, J L Muñoz Sanz, A Díaz Lantada, \\ J M Munoz-Guijosa, H Lorenzo Yustos, P Leal Wiña, and J Muñoz García \\ División de Ingeniería de Máquinas, Universidad Politécnica de Madrid, José Gutiérrez Abascal 2, Madrid, Spain
}

The manuscript was received on 1 December 2008 and was accepted after revision for publication on 27 February 2009.

DOI: 10.1243/13506501JET599

\begin{abstract}
This article shows different friction prediction models applicable to lubricants in point contacts under an elastohydrodynamic regime. The types of models used are two variations of the Newtonian theory, the Limiting Shear Stress model and the one based on Carreau's equation. The article sets out the theoretical calculation procedures and the ensuing equations for calculating the friction coefficient.

The aims of the article are to study the effect of the parameters with influence on friction and to compare the model's results with those given by an experimental stage performed on a mini traction machine. This test system allows the measurement of friction coefficient in point contacts (ball-disc) under a wide range of variation of parameters such as temperature, slide-roll ratio, lubricant, material, load, or velocity.
\end{abstract}

Keywords: friction, elastohydrodynamic lubrication, mini traction machine, rheological model, limiting shear stress, point contact

\section{INTRODUCTION}

The behaviour of mineral oils in elastohydrodynamic (EHD) point contacts and under severe operating conditions fails to comply with Newtonian formulation [1]. In these cases, this classical model is generally insufficient, which means that it is necessary to have recourse to new rheological behaviour models for the oil.

Thus, lubricants in EHD contacts can be considered non-Newtonian fluids and two other models are used to calculate the friction coefficient: the Limiting Shear Stress model $[\mathbf{2}, \mathbf{3}]$ and Carreau's Model [1]. They are particularly suited for predicting the friction (or traction) coefficient and observing the effect of the parameters with influence on friction.

The experimental stage was carried out on a mini traction machine (MTM) (PCS Instruments; http:// www.pcs-instruments.com), a test machine designed

\footnotetext{
* Corresponding author: División de Ingeniería de Máquinas, Universidad Politécnica de Madrid, José Gutiérrez Abascal 2, Madrid 28006, Spain.

email:jechavarri@etsii.upm.es
}

to obtain the friction (or traction) coefficient in lubricated point-type contacts. The tests carried out were used to verify the effect of the different variables on friction and to observe the correlation between the theoretical models and the experimental results obtained for these lubricants.

\section{NEWTON'S MODEL}

As a starting point, the Newtonian model for viscous fluids is applied to describe the lubricant behaviour. For the calculation of the shear stress, the following hypotheses are made.

1. The sliding component of the friction is taken into account [4], which is measured by the MTM.

2. The velocity gradient is taken as linear [4].

3. Film thickness is approached as constant in the whole of the contact and equal to the central film thickness $[\mathbf{3}, \mathbf{5}]$.

4. The increase in lubricant viscosity with the pressure is given by Barus' Law [6].

5. Circular point contact [4]

6. Hertzian parabolic pressure distribution, with a contact radius $a$ and a maximum pressure $p_{0}[\mathbf{5}]$. 
Under these conditions, Newtonian model shear stress $(\tau)$ is expressed as

$$
\tau=\eta_{0} \mathrm{e}^{\alpha p} \frac{\Delta U}{h_{\mathrm{Nc}}}
$$

where $\eta_{0}$ is the viscosity at atmospheric pressure, $\alpha$ is the pressure-viscosity coefficient, $p$ is the pressure, $\Delta U$ is the sliding velocity between surfaces, and $h_{\mathrm{Nc}}$ is the Newtonian central film thickness.

Therefore, by substituting pressure for the Hertzian distribution, integrating the shear stress and dividing by the load $(W)$, the Newtonian expression for the friction coefficient is obtained as

$$
\mu=3 \eta_{0} \frac{\Delta U}{h_{\mathrm{Nc}}} \frac{\exp \left(\alpha p_{0}\right)\left(\alpha p_{0}-1\right)+1}{\alpha^{2} p_{0}^{3}}
$$

\section{LIMITING SHEAR STRESS MODEL}

Studies on the rheology of lubricants $[\mathbf{7}, \mathbf{8}]$ reveal the existence of a shear stress at which point Newton's formulation is no longer valid [2]. This limiting shear stress $\left(\tau_{\mathrm{L}}\right)$ is dependent on the pressure and temperature

$$
\tau_{\mathrm{L}}=\tau_{0}+\zeta p
$$

In this model, both the limiting shear stress at atmospheric pressure $\left(\tau_{0}\right)$ and the dimensionless limiting shear stress-pressure parameter $(\zeta)$ are constants specific to each lubricant. The parameter $\zeta$ incorporates the influence of temperature.

The simplified model considered constitutes an approach [3], which consists in taking account of the Newtonian model until limiting shear stress is reached. From then on, shear stress is considered to take on its boundary value. That is

$$
\begin{aligned}
& \text { Newtonian behaviour: } \tau=\eta_{0} \mathrm{e}^{\alpha p} \frac{\Delta U}{h_{\mathrm{Nc}}} \\
& \text { Non-Newtonian behaviour: } \tau=\tau_{\mathrm{L}}=\tau_{0}+\zeta p
\end{aligned}
$$

Therefore, the contact area can be divided into two integration domains. The difficulty resides in finding the transition points, where the following equation is fulfilled

$$
\eta_{0} \mathrm{e}^{\alpha p} \frac{\Delta U}{h_{\mathrm{Nc}}}=\tau_{0}+\zeta p
$$

By carrying out an iteration, the value of the pressure reached at the limiting shear stress $\left(p^{*}\right)$ is found, where the transition between the Newtonian and nonNewtonian behaviour of the lubricant is produced.
The final aim is to calculate the radius $(b)$ in which a change in oil behaviour is produced

$$
b=a \sqrt{1-\left(\frac{p^{*}}{p_{0}}\right)^{2}}
$$

By calling $r$ the radius of the contact zone, the Newtonian domain will correspond to the outermost zone $(a>r>b)$, while in the innermost zone $(b<r<0)$ the concept of limiting shear stress will be applied. Therefore, the friction force is

$$
F_{\mu}=\int_{b}^{a} \eta_{0} \mathrm{e}^{\alpha p} \frac{\Delta U}{h_{\mathrm{Nc}}} 2 \pi r \mathrm{~d} r+\int_{0}^{b}\left(\tau_{0}+\zeta p\right) 2 \pi r \mathrm{~d} r
$$

By substituting pressure for the Hertzian distribution and dividing by the load $(W)$, the final expression for the friction coefficient is obtained as

$$
\begin{aligned}
\mu= & 3 \eta_{0} \frac{\Delta U}{h_{\mathrm{Nc}}} \frac{\exp \left(m \alpha p_{0}\right)\left(m \alpha p_{0}-1\right)+1}{\alpha^{2} p_{0}^{3}} \\
& +\zeta\left(1-m^{3}\right)+\frac{3 \tau_{0}}{2 p_{0}}\left(1-m^{2}\right)
\end{aligned}
$$

where the maximum pressure or Hertz pressure $\left(p_{0}\right)$ is

$$
p_{0}=\frac{3 W}{2 \pi a^{2}}
$$

with a semi-width (radius) of the contact

$$
a=\sqrt[3]{\frac{3 W R}{4 E^{*}}}
$$

This parameter includes the influence of Young's reduced modulus $\left(E^{*}\right)$ of the contact materials and the reduced radius of curvature $(R)$ of the surfaces.

The parameter $m$, which measures the relation between the transition radius $(b)$ and the contact radius $(a)$, has been inserted into equation (8)

$$
m=\sqrt{1-\left(\frac{b}{a}\right)^{2}}
$$

In addition, having obtained the expression for the friction coefficient (8) using the Limiting Shear Stress model, it is possible to deduce the expression for the friction coefficient for Newton's model (2), by substituting the parameter $m$ for 1 .

The high pressure in elastohydrodynamic lubrication (EHL) usually produces the pressure-dependent part to become dominant in equation (3), according to references [9] and [10]. Thus, the limiting shear stress at atmospheric pressure $\left(\tau_{0}\right)$ can be neglected in most cases, simplifying the use of equations (5) and (8). 


\section{CARREAU'S MODEL}

Another way to analyse lubricant rheology $[\mathbf{1}, \mathbf{1 1}]$ is by assuming that actual viscosity in the contact is less than that indicated by Barus' law. Thus, if $h_{\mathrm{c}}$ is the non-Newtonian film thickness, generalized viscosity is given by Carreau's equation [12], which, for this case, can be expressed as

$$
\eta=\eta_{0} \mathrm{e}^{\alpha p}\left[1+\left(\frac{\eta_{0} \mathrm{e}^{\alpha p}\left(\Delta U / h_{\mathrm{c}}\right)}{G}\right)^{2}\right]^{(n-1) / 2}
$$

Exponent $n$ is specific to the lubricant and $G$ is its shear modulus. The relative viscosity is defined as

$$
\frac{\eta}{\eta_{0} \mathrm{e}^{\alpha p}}=\left[1+\left(\frac{\eta_{0} \mathrm{e}^{\alpha p}\left(\Delta U / h_{\mathrm{c}}\right)}{G}\right)^{2}\right]^{(n-1) / 2}
$$

Bair [13] used a modified Carreau equation with shear stress as the independent variable, which gives viscosity results very similar to that of Carreau's equation (13) for $0.2<n<1$

$$
\frac{\eta}{\eta_{0} \mathrm{e}^{\alpha p}}=\left[1+\left(\frac{\tau}{G}\right)^{2}\right]^{(1-(1 / n))(1 / 2)}
$$

The modified Carreau equation has been applied to point and line contacts lubricated with PAO $[\mathbf{1 3}, \mathbf{1 4}]$. Figure 1 shows the relation between relative viscosity

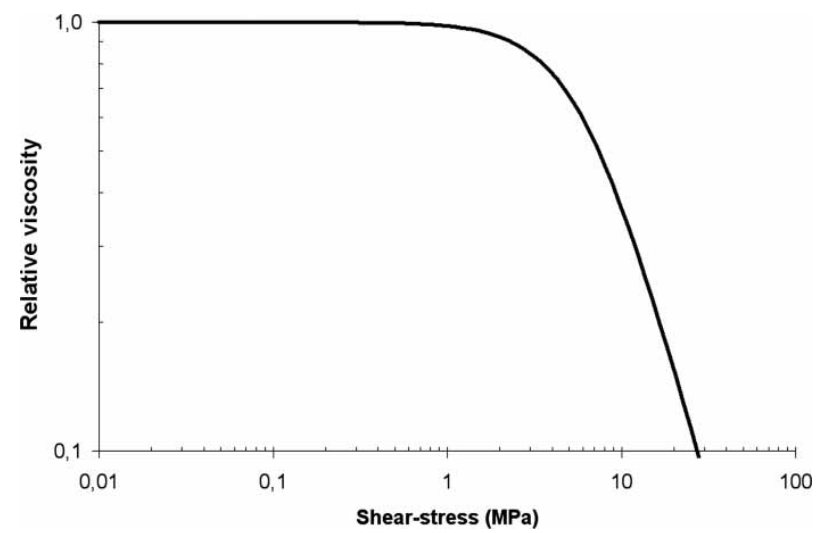

Fig. 1 Relative viscosity of Carreau's model for a PAO-40 at $25^{\circ} \mathrm{C}$ and shear stress for a lubricant PAO- 40 at $25^{\circ} \mathrm{C}[\mathbf{1 3}]$. As shear stress rises, the rheological model considers a reduction in the relative viscosity.

The calculating process consists of inserting this corrected (or generalized) viscosity into Newton's law for viscous fluids. Thus, according to Carreau's model (equation (13)), shear stress can be expressed as

$$
\tau=\eta \frac{\Delta U}{h_{\mathrm{c}}}=\eta_{0} \mathrm{e}^{\alpha p}\left[1+\left(\frac{\eta_{0} \mathrm{e}^{\alpha p}\left(\Delta U / h_{\mathrm{c}}\right)}{G}\right)^{2}\right]^{(n-1) / 2} \frac{\Delta U}{h_{\mathrm{c}}}
$$

By integrating the shear stress in the contact area and dividing by the load, the friction coefficient equation is found

$$
\mu=3\left(\eta_{0} \frac{\Delta U}{h_{\mathrm{c}}}\right)^{n} G^{1-n} \frac{\exp \left(n \alpha p_{0}\right)\left[n \alpha p_{0}-1\right]+1}{(n \alpha)^{2} p_{0}^{3}}
$$

Equation (16) has been obtained by assuming a value of the Newtonian shear stress substantially higher than the parameter $G$ for most part of the contact area. Otherwise, the integration process for equation (15) should be made numerically.

\section{EXPERIMENTATION}

\subsection{Mini traction machine}

Figure 2 shows the test equipment the MTM used to obtain the sliding component of the friction coefficient in lubricated point-type contacts. The equipment comprises a ball and a disc in contact, moved by independent axes, submerged in a reservoir full of lubricant at a controlled temperature. Therefore, both ball and disc can rotate independently at different speeds, that is, different values can be chosen for the slide-roll ratio $(\mathrm{SRR})=100 \Delta U / U$, which relates the sliding velocity $(\Delta U)$ with the average velocity $(U)$.

\subsection{Test programme}

Having analysed equations (2), (8), and (16) obtained for the friction coefficient using different models,
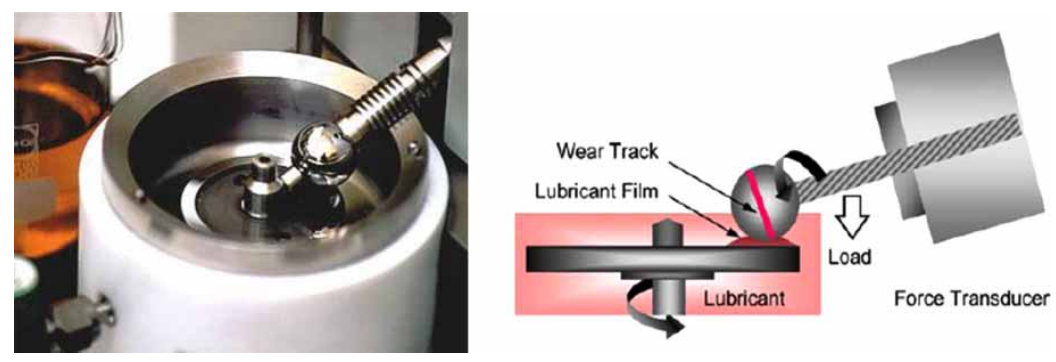

Fig. 2 Photograph and diagram of the test zone in the MTM 
it can be deduced that the following variables are involved in its calculation.

1 . Viscosity at atmospheric pressure $\left(\eta_{0}\right)$ and the pressure-viscosity coefficient $(\alpha)$ are variables specific to each type of lubricant and vary with temperature $(T)$.

2. Hertzian pressure $\left(p_{0}\right)$ depends on the load $(W)$, the elasticity of the specimen materials $\left(E^{*}\right)$, and the reduced radius of curvature $(R)$ of the surfaces.

3. Sliding velocity $(\Delta U)$ is directly affected by the SRR and the average velocity of the surfaces $(\mathrm{SRR}=$ $100 \Delta U / U)$.

4. Film thickness $\left(h_{\mathrm{c}}\right)$ depends on parameters related to the load conditions, materials, velocity, temperature, and lubricant [7].

5. Variables associated with a non-Newtonian behaviour of the lubricant: for the Limiting Shear Stress model $\left(\tau_{0}, \zeta\right)$ and Carreau's model $(n, G)$.

Thus, most of the parameters with influence can be fitted or controlled in the MTM. Velocity, temperature, load, and the SRR are test input parameters, while others depend on the lubricant to be tested and the specimen materials. The test plan includes the following experimental ranges.

1. Velocity $(U): 10-3000 \mathrm{~mm} / \mathrm{s}$.

2. Temperature $(T): 30,40,60,80$, and $100^{\circ} \mathrm{C}$.

3. Load $(W): 20$ and $28 \mathrm{~N}$.

4. Materials: steel-steel and steel-copper.

5. SRR: 5 and 25 per cent.

6. Lubricant: mineral base and polyalphaolefin PAO-6.

The properties of the testing materials are shown in Table 1.Young's reduced modulus $\left(E^{*}\right)$ is deduced from Table 1 for the contacts tested: steel-steel $(115 \mathrm{GPa})$ and steel-copper (84 GPa). In the following equations (17) to (19), Young's reduced modulus is expressed as $E=2 E^{*}$.

The physical properties of the mineral base and the polyalphaolefin (PAO-6) used are shown in Table 2

$[9,15]$. Viscosity was measured in the laboratory. For the limiting shear stress at atmospheric pressure, a reference value of $\tau_{0}=4 \mathrm{MPa}$ is indicated in the literature [10]. However, the pressure reached in all the tests cited is large enough so as to neglect the parameter $\tau_{0}$ for the calculations. The parameters of the lubricant $n$ and $G$ may be fitted in line with the experimental results $[\mathbf{1 3}]$.

Table 1 Properties of materials used in the tests

\begin{tabular}{lll}
\hline Material & $\begin{array}{l}E(\mathrm{GPa}) \text { Young's } \\
\text { modulus }\end{array}$ & $\begin{array}{l}v \text { Poisson's } \\
\text { ratio }\end{array}$ \\
\hline Steel E-52100 & 210 & 0.30 \\
Copper & 117 & 0.34 \\
\hline
\end{tabular}

Table 2 Properties of the mineral base and the polyalphaolefin

\begin{tabular}{|c|c|c|c|c|c|c|}
\hline \multirow[b]{2}{*}{$\begin{array}{l}T \\
\left({ }^{\circ} \mathrm{C}\right)\end{array}$} & \multicolumn{3}{|c|}{ Mineral oil } & \multicolumn{3}{|c|}{ Polyalphaolefin (PAO-6) } \\
\hline & $\begin{array}{l}\eta_{0} \\
(\mathrm{mPa} \mathrm{s})\end{array}$ & $\begin{array}{l}\alpha \\
\left(\mathrm{GPa}^{-1}\right)\end{array}$ & $\zeta$ & $\begin{array}{l}\eta_{0} \\
(\mathrm{mPa} \mathrm{s})\end{array}$ & $\begin{array}{l}\alpha \\
\left(\mathrm{GPa}^{-1}\right)\end{array}$ & $\zeta$ \\
\hline 30 & 36.25 & 16.8 & 0.0455 & 37.95 & 12.3 & 0.0403 \\
\hline 40 & 23.38 & 15.7 & 0.0445 & 25.00 & 11.5 & 0.0395 \\
\hline 60 & 11.51 & 13.9 & 0.0432 & 12.57 & 10.1 & 0.0389 \\
\hline 80 & 6.66 & 12.6 & 0.0422 & 7.36 & 9.0 & 0.0384 \\
\hline 100 & 4.22 & 11.4 & 0.0414 & 4.78 & 8.2 & 0.0380 \\
\hline
\end{tabular}

\subsection{MTM work regime}

The MTM enables the velocity to be regulated within a wide range, which means the three main lubricating regimes can be distinguished: boundary, mixed, and (elasto)hydrodynamic. In this last area, the HamrockDowson chart $[4,7, \mathbf{1 6}]$ has been used to observe the work regime. In this graph, the expressions for the parameters of viscosity $\left(g_{\mathrm{V}}\right)$ and elasticity $\left(g_{\mathrm{E}}\right)$ are as follows

$$
g_{\mathrm{V}}=\frac{\alpha W^{3}}{\left(\eta_{0} U\right)^{2} R^{4}}, \quad g_{\mathrm{E}}=\frac{W^{8 / 3}}{\left(\eta_{0} U\right)^{2} E^{2 / 3} R^{10 / 3}}
$$

Figure 3 shows the location of the EHD operating conditions during tests in the Hamrock-Dowson chart [16, 17], their being under a piezoviscous-elastic regime (P-E). Therefore, the classical Hamrock and Dowson [18] film thickness formula is applicable for calculating the Newtonian central film thickness in isothermal EHL $\left(h_{\mathrm{Nc}}\right)$

$$
h_{\mathrm{Nc}}=1.55 \alpha^{0.53}\left(\eta_{0} U\right)^{0.67} E^{\prime 0.061} R^{0.33} p_{0}^{-0.201}
$$

The film thickness reduction due to thermal effects has been examined by different authors $[\mathbf{1 9}, \mathbf{2 0}]$. Hamrock [16], based on Gupta et al. [20], proposes the following empirical formula

$$
\varphi_{\mathrm{T}}=\frac{1-13.2\left(p_{0} / E^{\prime}\right) L^{0.42}}{1+0.213\left[1+2.23(\Delta U / U)^{0.83}\right] L^{0.64}}
$$

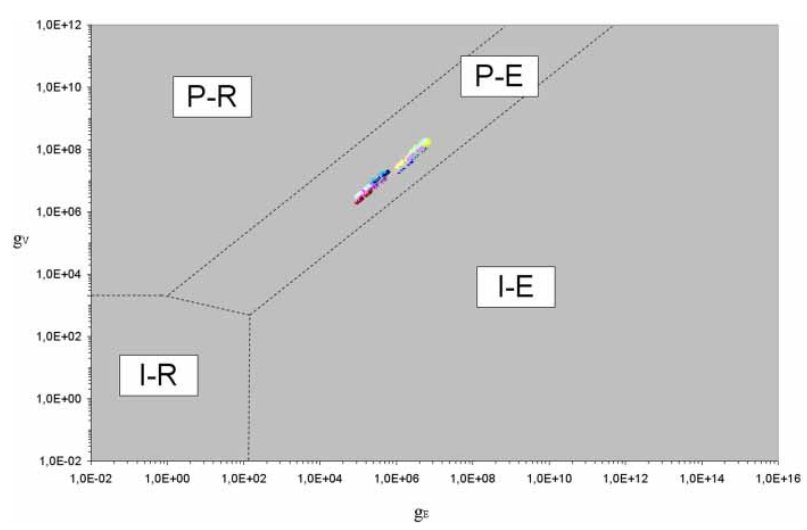

Fig. 3 Location of the test conditions in the HamrockDowson chart 
where $L \approx \beta \eta_{0} U^{2} / K$ is a thermal loading factor, $\beta$ is the temperature-viscosity coefficient, and $K$ is the thermal conductivity of the lubricant. $\varphi_{\mathrm{T}}<1$ is a thermal factor, which multiplied by the Hamrock and Dowson film thickness provides a corrected value of $h_{\mathrm{Nc}}$ including thermal effects. The thermal factor can be used for predicting the occurrence of significant thermal effects in point contacts [21]. When $\varphi_{\mathrm{T}}$ is close to one, the regime is considered approximately isothermal.

Newtonian central film thickness is corrected for shear thinning by using a simple formula of Bair and Winer [22] for Carreau's model

$$
\frac{h_{\mathrm{Nc}}}{h_{\mathrm{c}}}=\left[1+4.44\left(\frac{U \eta_{0}}{h_{\mathrm{Nc}} G}\right)^{1.69}\right]^{1.26(1-n)^{1.78}}
$$

In a previous work [14], the calculation of the nonNewtonian film thickness $\left(h_{\mathrm{c}}\right)$ has shown to improve the central film thickness theoretical calculation for point contacts.

Once the non-Newtonian film thickness $\left(h_{\mathrm{c}}\right)$ and the surface roughness $\left(\sigma_{1}\right.$ and $\left.\sigma_{2}\right)$ are known, the film thickness parameter $(\lambda)$ can be calculated $[2]$

$$
\lambda=\frac{h_{\mathrm{c}}}{\sqrt{\sigma_{1}^{2}+\sigma_{2}^{2}}}
$$

The surface roughness measured for the specimens is $\sigma=2.24 \times 10^{-8} \mathrm{~m}$. The value $\lambda=3$ of this film parameter allows the limit between the mixed lubrication regime and the EHD regime to be set [8]. For the MTM equipment, a minimum velocity of approximately $2000 \mathrm{~mm} / \mathrm{s}$ has been calculated, according to equations (18) to (21), to determine the limits of the EHD regime in the experimentation. Thus, the lubrication regime can be taken as EHD for velocities above approximately $2000 \mathrm{~mm} / \mathrm{s}$.

\section{RESULTS ANALYSIS AND DISCUSSION}

\subsection{Theoretical and experimental responses to variations in the parameters with influence}

Friction force is the result of integrating shear stress $(\tau)$ in the contact area. Therefore, by using the simplified Limiting Shear Stress model a first approach for the friction coefficient is obtained when an EHD contact reaches the non-Newtonian behaviour. As a result, a prediction for the effect of the different parameters with influence on the shear stress can be analysed and the results extended to the friction coefficient.

In most of the testing conditions indicated in section 5.2, the thermal reduction in film thickness is below 5 per cent for both the mineral oil and the PAO, when estimated with equation (19). Therefore, the EHL regime can be considered approximately isothermal. The thermal conductivity reference value at $80^{\circ} \mathrm{C}$ is $0.12 \mathrm{~W} / \mathrm{m}^{\circ} \mathrm{C}$ for the mineral oil and $0.15 \mathrm{~W} / \mathrm{m}^{\circ} \mathrm{C}$ for the PAO-6, and these values vary with pressure and temperature [23].

\subsubsection{Temperature}

The effect of a rise in temperature on the model is that the viscosity $\left(\eta_{0}\right)$ and pressure-viscosity coefficient $(\alpha)$ fall. According to equation (1), the shear stress decreases and a delay is caused in reaching the non-Newtonian conditions. A rise in temperature also leads to a slight decrease in the limiting shear stresspressure coefficient $(\zeta)$ that involves a decrease in the shear stress, as can be observed in equation (3).

The results for the mineral base are shown in Fig. 4(a), it can be appreciated how the shear stress is less at $80^{\circ} \mathrm{C}$ than at $40^{\circ} \mathrm{C}$ in the two zones (Newtonian and non-Newtonian), which means the integration area is smaller and a decrease in the friction coefficient is to be expected. Indeed, experimentally, a decrease in friction coefficient can be observed (Fig. 4(b)) in the EHD zone as the temperature increases.

\subsubsection{Load}

An increase in load leads to an increase in maximum pressure $\left(p_{0}\right)$ and the half width of contact (a). This causes the lubricant to behave like a nonNewtonian fluid in more contact area, and so limiting shear stress is reached sooner. Figure 5(a) reflects the increase in the integration area obtained by taking into

(a)
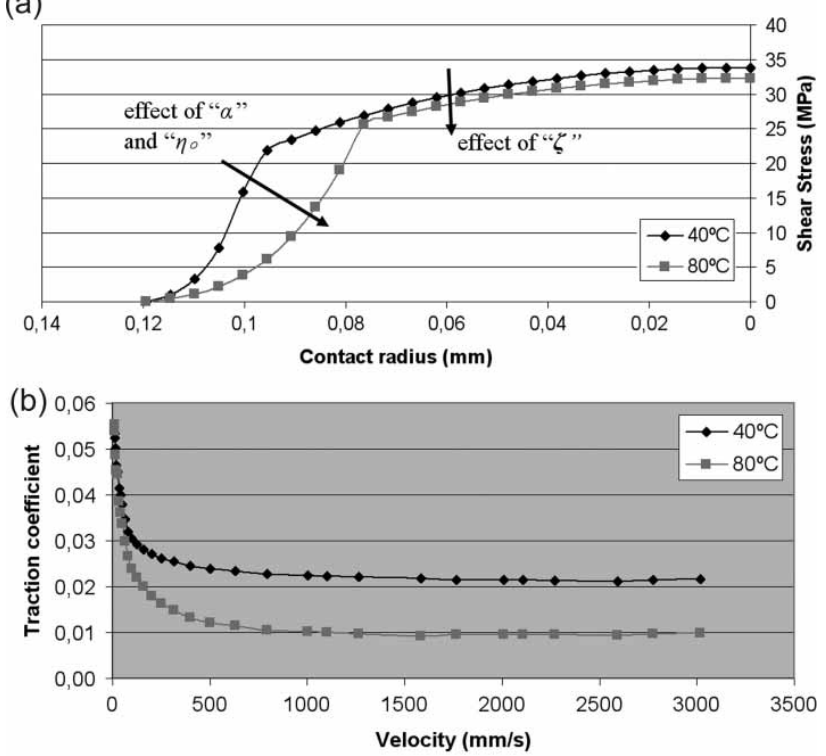

Fig. 4 Steel-copper contact lubricated with mineral base, load: $20 \mathrm{~N}$; SRR $=25$ per cent; (a) theoretical effect of temperature on shear stress for $U=3000 \mathrm{~mm} / \mathrm{s}$; and (b) experimental influence of temperature on friction coefficient 
account equations (1) and (3). By extension, the friction coefficient increases in the whole EHD region of the experimental curve, as can be seen in Fig. 5(b).

\subsubsection{Materials}

As Young's reduced modulus in the contact increases $\left(E^{*}\right)$, the contact radius $(a)$ decreases. At the same time, the maximum pressure rises and the non-Newtonian behaviour of the lubricant is reached in more contact area. The combination of both effects can be seen in Fig. 6(a), given by expressions (1) and (3).

The effect of a rise in pressure $p_{0}$ is much greater than that of a decrease in radius $(a)$, with the shear stress integration area being increased. The main increase is produced in the non-Newtonian domain, due to the considerable influence of the pressure on the limiting shear stress (3), which means that in the case of steelsteel the friction coefficient is greater, as observed in Fig. 6(b).

\subsubsection{Slide-roll ratio}

Taking equations (1) and (3), a higher SRR can lead to non-Newtonian behaviour in more contact area. The results shown in Fig. 7(a) are reasonable since a higher SRR involves an increase in sliding and, thus, a faster rise in shear stress. When non-Newtonian behaviour has been reached in both cases (SRR $=5$ per cent and $\mathrm{SRR}=25$ per cent), there are no differences in the value of limiting shear stress, as the same conditions

(a)
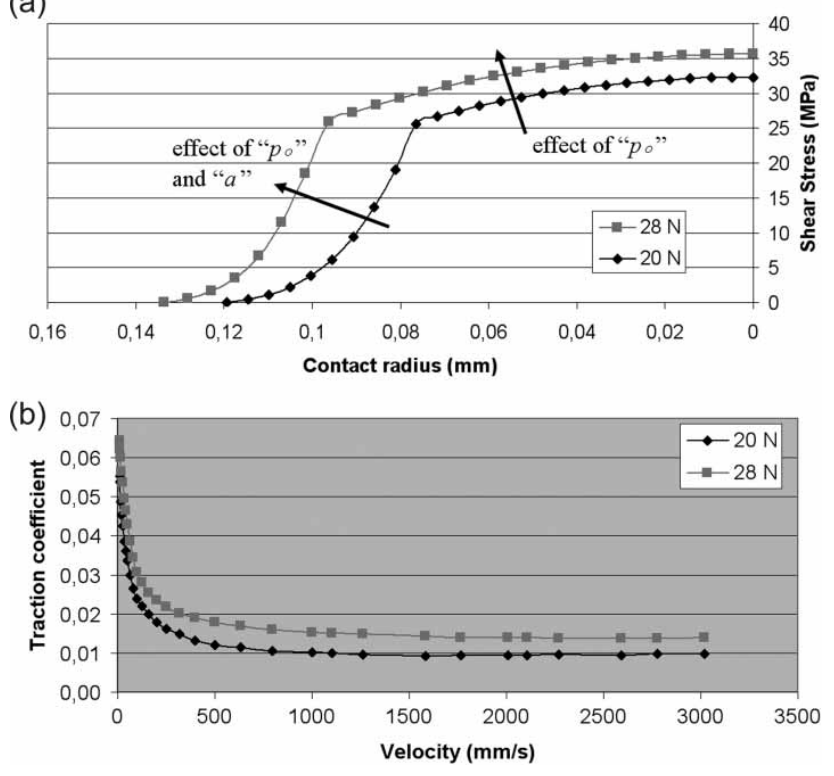

Fig. 5 Steel-copper contact lubricated with mineral base, temperature: $80^{\circ} \mathrm{C}$; SRR $=25$ per cent; (a) theoretical effect of load on shear stress and the contact radius for $U=3000 \mathrm{~mm} / \mathrm{s}$; and (b) experimental influence of load on friction coefficient of pressure and temperature exist (Fig. 7(a)). It can be seen that the increase in the integration area, and by extension, in the experimental friction coefficient (Fig. 7(b)), has its origins in the Newtonian domain.

(a)
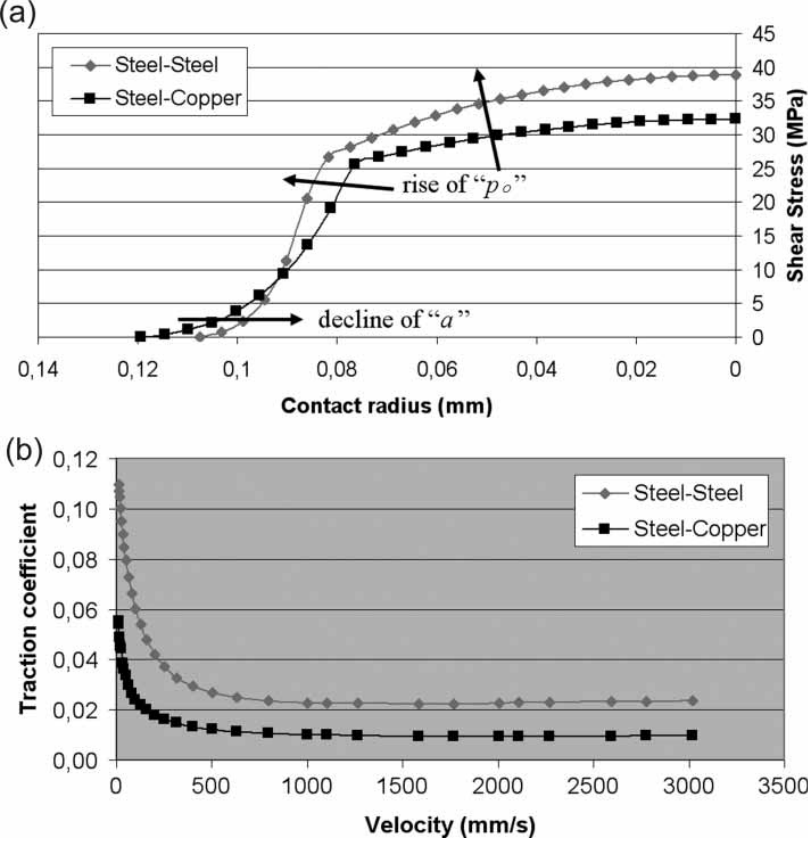

Fig. 6 Contact lubricated with mineral base, temperature: $80^{\circ} \mathrm{C}$; load: $20 \mathrm{~N}$; SRR $=25$ per cent; (a) theoretical effect of materials on shear stress and contact radius for $U=3000 \mathrm{~mm} / \mathrm{s}$; and (b) experimental influence of material on friction coefficient
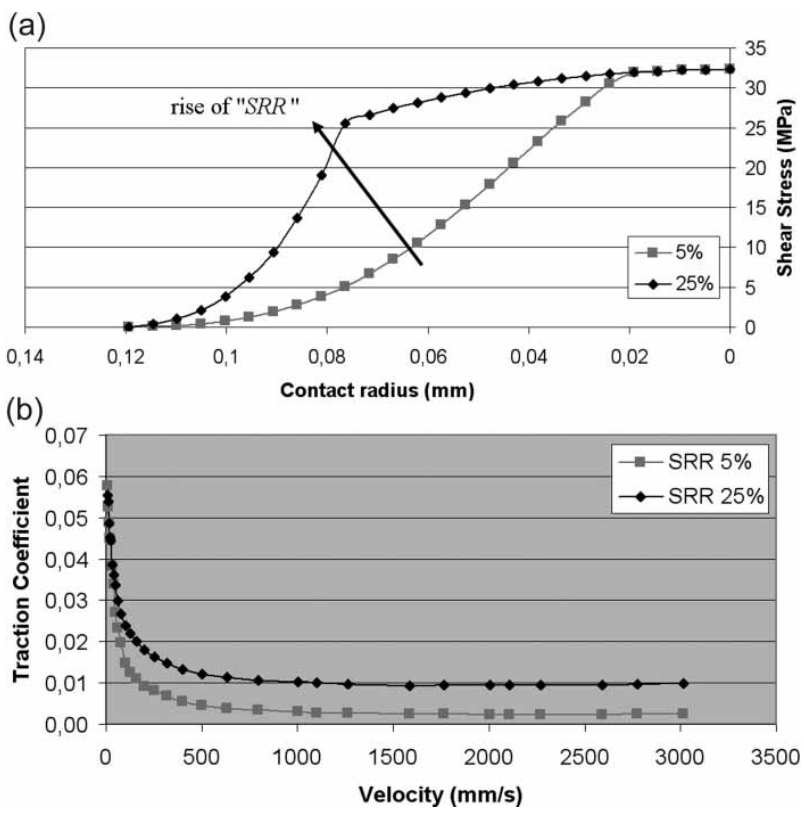

Fig. 7 Steel-copper contact lubricated with mineral base, temperature: $80^{\circ} \mathrm{C}$; load: $20 \mathrm{~N}$; (a) effect of SRR on shear stress for $U=3000 \mathrm{~mm} / \mathrm{s}$; and (b) experimental influence of SRR on friction coefficient 


\subsubsection{Lubricant}

In the case analysed for a polyalphaolefin (PAO-6), the latter behaves like a Newtonian fluid in the whole of the contact zone, at no time reaching limiting shear stress (Fig. 8(a)). This Limiting Shear Stress model appropriately predicts a decrease in the friction of the polyalphaolefin with respect to the mineral base, as depicted in Fig. 8(b), the main reason for which is its lower pressure-viscosity coefficient value $(\alpha)$.

\subsection{Predicting the friction coefficient}

Figure 9(a) shows the theoretical prediction according to the Limiting Shear Stress model and the experimental results for a steel-copper contact lubricated with the PAO-6, using SRR $=25$ per cent, at $80^{\circ} \mathrm{C}$ and with $20 \mathrm{~N}$ of load.

The friction coefficient calculated is higher because the shear stress is overvalued. This is particularly due to the failure to take account of a transition zone between Newtonian and non-Newtonian behaviour ('Newtonian' and 'Viscoplastic' straight lines depicted in Fig. 9(b)), which is taken into account in the more mathematically complex rheological models also shown in Fig. 9(b) [16]. Similar results are obtained for all the testing conditions considered. Therefore, for predicting the value of the friction coefficient, other more complex models are required, like Carreau's equation.

(a)
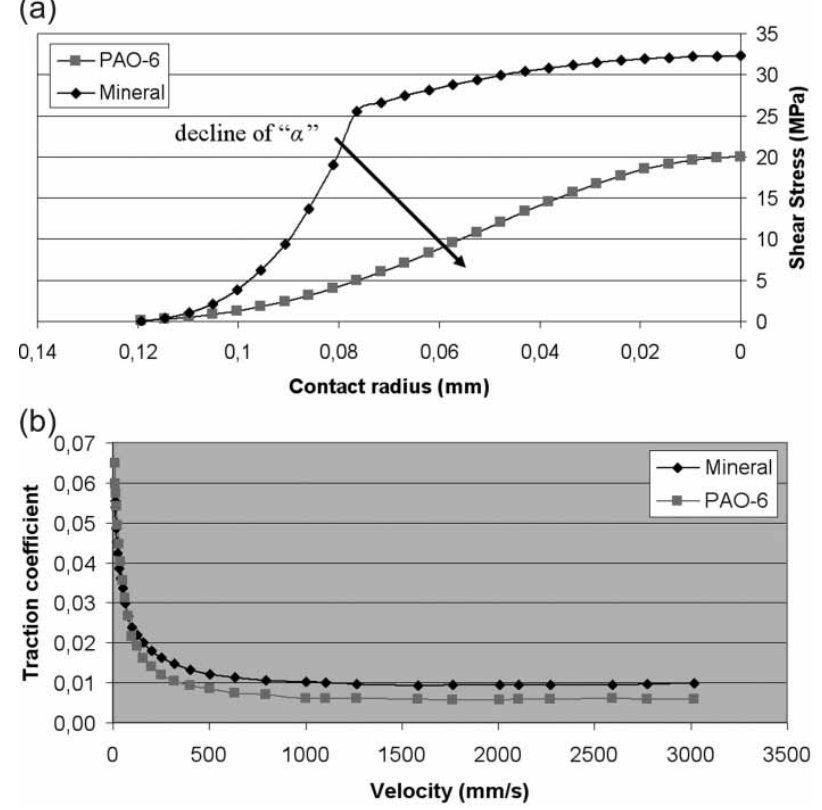

Fig. 8 Steel-copper contact lubricated, temperature: $80^{\circ} \mathrm{C}$; load: $20 \mathrm{~N}$; SRR $=25$ per cent; (a) effect of lubricant (Mineral and PAO-6) on shear stress for $U=3000 \mathrm{~mm} / \mathrm{s}$; and (b) experimental influence of lubricant on friction coefficient
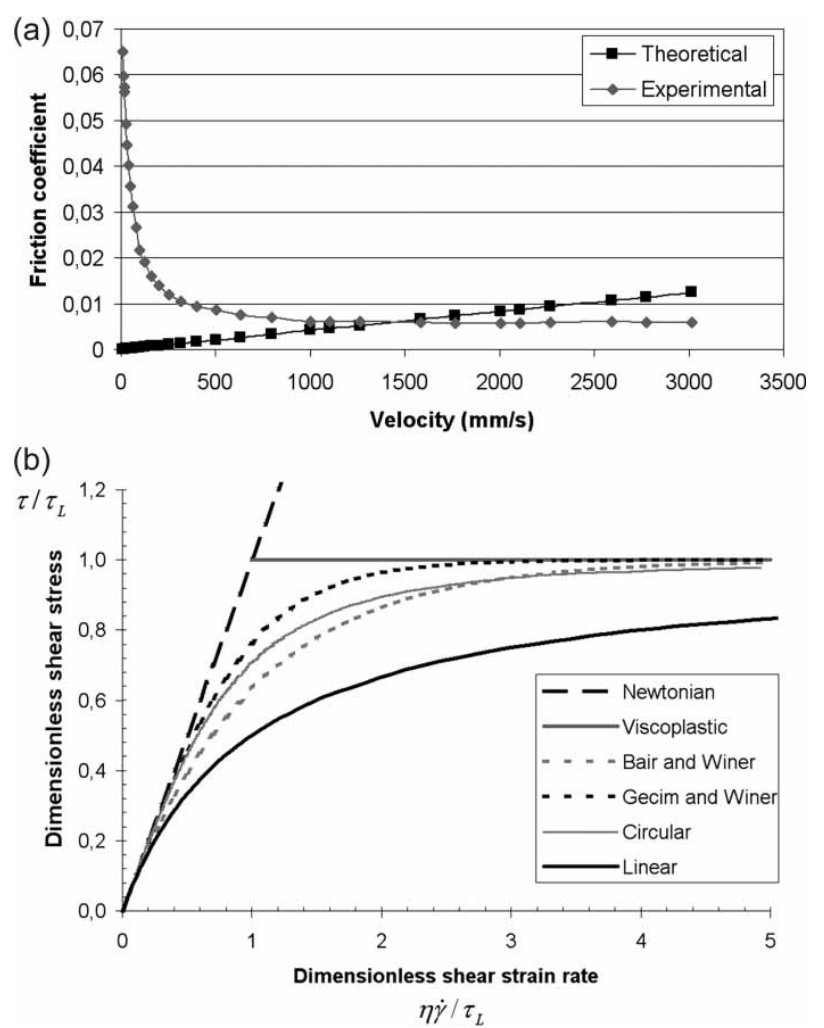

Fig. 9 (a) Comparison between experimental results and the Limiting Shear Stress model for the PAO-6. Steel-copper contact at $80^{\circ} \mathrm{C}$, load: $20 \mathrm{~N}$; $\mathrm{SRR}=25$ per cent; and (b) different rheological models for lubricants

In this model, the film thickness calculation is based on equation (18), corrected by the thermal factor (equation (19)) and the simple formula (20). The parameters $n$ and $G$, which vary with temperature, and less importantly, with pressure [24], must be fitted through previous tests, using two different conditions for each temperature, to obtain two equations (16) that allow the deduction of the parameters $n$ and $G$.

When thermal effects are important, these parameters must be calculated by using two previous tests not only at the same bulk temperature but also with equivalent thermal effects in the contact. In this case, the decrease in viscosity can be estimated by comparing the thermal and isothermal film thickness. As the viscosity-temperature relation is known, an average real inlet temperature can be obtained for the lubricant.

As commented before, for the testing conditions used in this article, the EHD lubrication regime can be considered approximately isothermal. However, the non-Newtonian effect has shown to produce a significant reduction in the film thickness and therefore has been considered in the calculations.

The values obtained for the two previous tests carried out in the MTM at $80^{\circ} \mathrm{C}$ and $20 \mathrm{~N}$ are $n=0.81$ and $G=1.0 \times 10^{5} \mathrm{~Pa}$. By way of example, Fig. 10 shows 


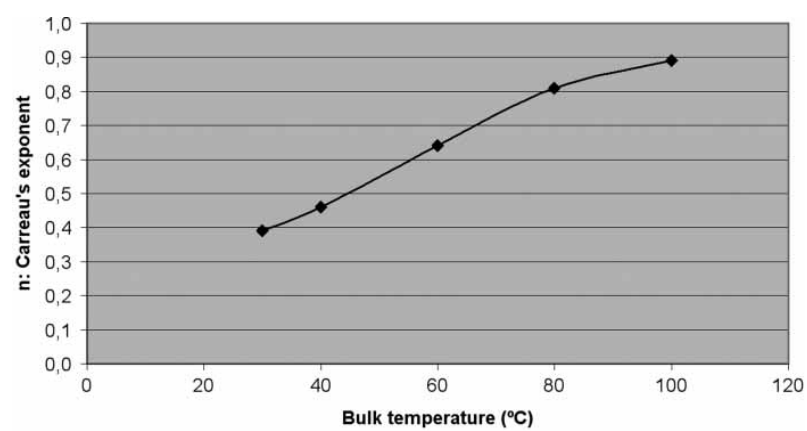

Fig. 10 Influence of temperature on exponent $n$ for the PAO-6

the values obtained for the PAO- 6 for $n$ depending on the bulk temperature. Table 3 compares the values obtained for $n$ and $G$ with those consulted in the bibliography $[13,14]$ for polyalphaolefins of different viscosity at different temperatures.

In Fig. 11, the shear stress profile for the PAO-6 obtained using Carreau's equation is compared with the Limiting Shear Stress model. An important reduction in the shear stress is found with Carreau's formulation, which leads to a reduction in the friction coefficient calculated. The simplified model indicates that the limiting shear stress is not reached and therefore Fig. 11 reflects an increase in the divergence between 'Newtonian' and 'Carreau' curves in the maximum pressure zone, which is in line with Fig. 9(b) for a value lower than one of the dimensionless shear strain rate.

Table 3 Fitting $n$ and $G$ for different polyalphaolefins

\begin{tabular}{lllll}
\hline & $\begin{array}{l}\text { Temperature } \\
\text { Lubricant }\end{array}$ & $\begin{array}{l}\text { Shear } \\
\text { modulus } \\
(G)\end{array}$ & $\begin{array}{l}\text { Carreau's } \\
\text { exponent } \\
(n)\end{array}$ & Reference \\
\hline PAO-650 & 20 & $3.1 \times 10^{4} \mathrm{~Pa}$ & 0.74 & {$[\mathbf{1 4}]$} \\
PAO-40 & 25 & $6.0 \times 10^{6} \mathrm{~Pa}$ & 0.40 & {$[\mathbf{1 3}]$} \\
PAO-6 & 80 & $1.0 \times 10^{5} \mathrm{~Pa}$ & 0.81 & This article \\
\hline
\end{tabular}

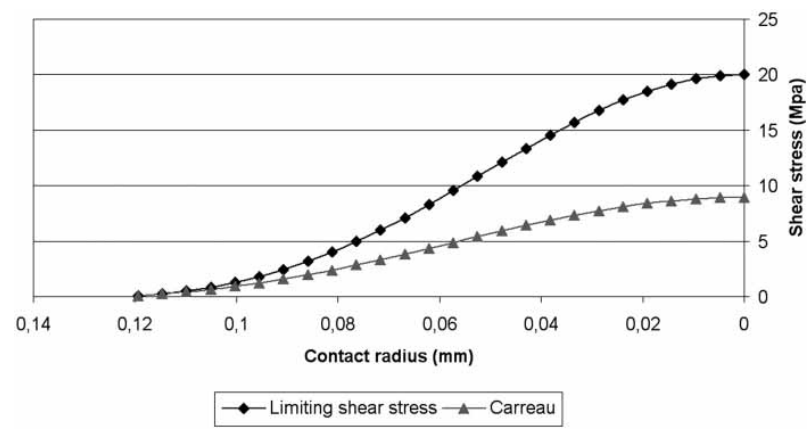

Fig. 11 Comparison between shear stress profile calculated with Carreau's equation and the Limiting Shear Stress model. Steel-copper contact lubricated with PAO-6, load: $20 \mathrm{~N}$; SRR $=25$ per cent; $U=3000 \mathrm{~mm} / \mathrm{s}$
Carreau Model. Steel-Copper. 20N. $80^{\circ}$ C. SRR 25\%

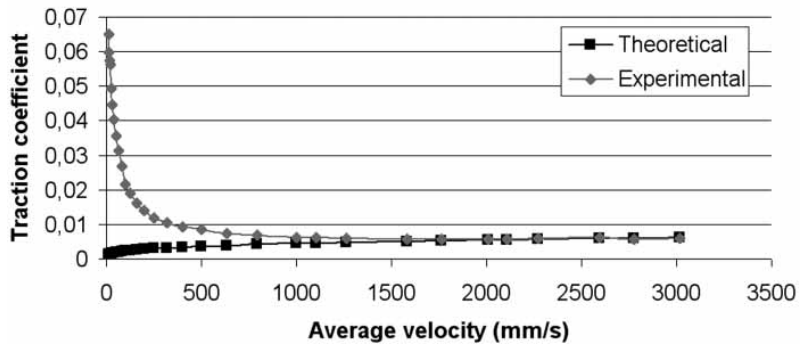

Fig. 12 Comparison between the theoretical prediction for a PAO- 6 according to Carreau's model with the experimental results obtained in the MTM

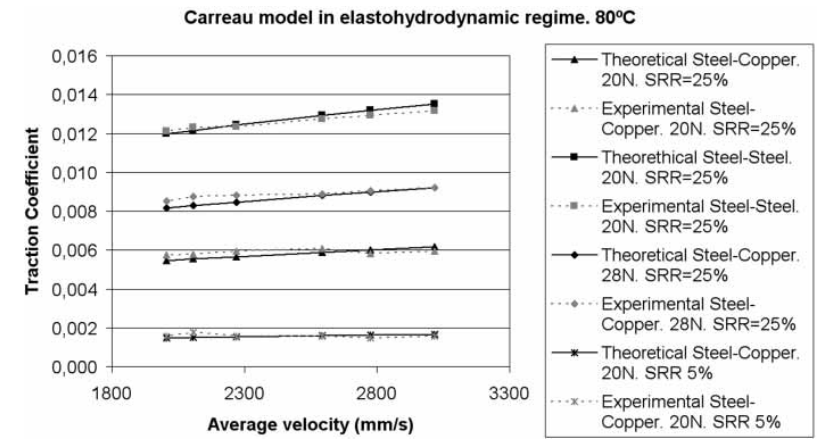

Fig. 13 Comparison between Carreau's model for a PAO- 6 and the experimental results in the EHD region

Figure 12 shows a comparison of the theoretical results obtained for the PAO-6 by applying Carreau's model with those obtained experimentally with the MTM for steel-copper contact at $80^{\circ} \mathrm{C}$ under a load of $20 \mathrm{~N}$ and $\mathrm{SRR}=25$ per cent. The results indicate a high degree of correlation between predicted and experimental data. It should be remembered that the lubrication regime can be taken as EHD for velocities above $\sim 2000 \mathrm{~mm} / \mathrm{s}$.

Figure 13 shows a broader theoretical-experimentation comparison under the EHD regime $(2000<$ $U<3000 \mathrm{~mm} / \mathrm{s}$ ). As can be seen, when the contact materials, the load, or the SRR are changed, the Carreau model perfectly describes the friction behaviour of the lubricant in the EHD region. The same occurs when other parameters are varied, showing in most cases deviations below 7 per cent between predicted and experimental data, once the $n$ and $G$ parameters have been fitted to each temperature.

\section{CONCLUSIONS}

Theoretical analytical models have been obtained for estimating friction coefficient. The test plan performed on the MTM enables these models to be verified as well as to develop a study of the variables with influence on the phenomenon. 
The Limiting Shear Stress model is a powerful tool for analysing the effect of the parameters with influence on friction in the EHD regime. Dividing the contact into two lubricant behaviour zones makes it easier to see how the regions change as the variables with influence are altered. A predictive analysis of the effect of the variables with influence on friction has been made and the results have been verified experimentally using an MTM over a wide operational range.

The Limiting Shear Stress model overestimates friction unless a detailed transition of non-Newtonian to Newtonian behaviour is taken into account. From a precision point of view, Carreau's model fits perfectly to the experimental results in all the tests performed, although it needs to be fitted to each temperature for the $n$ and $G$ values of the model.

\section{ACKNOWLEDGEMENTS}

This work was carried out as part of a Project financed by the Repsol Foundation. The authors thank Jorge Insa and Luis Fernández of the Lubricants Laboratory of Repsol-YPF's Technology Department for their valuable collaboration.

\section{REFERENCES}

1 Bair, S. and Winer, W. O. Some observations in high pressure rheology of lubricants. Trans. ASME, J. Lubr. Technol., 1982, 104, 357.

2 Dowson, D. Elastohydrodynamic and micro-elastohydrodynamic lubrication. Wear, 1995, 190, 125-138.

3 Ge, P. and Liu, Z. Experimental and computational investigation of the friction coefficient of a ball friction drive device. Tribol. Int., 2002, 35, 219-224.

4 De Vicente, J., Stokes, J. R., and Spikes, H. A. The frictional properties of Newtonian fluids in rolling-sliding soft-EHL contact. Tribol. Lett., 2005, 20(3-4), 273-286.

5 Hertz, H. On the contact of elastic solids. In Miscellaneous papers (Eds H. Hertz, D. E. Jones, and G. A. Schort), 1896, pp. 146-162 (Macmillan, London).

6 Barus, C. Isotherms, isopiestics and isometrics relative to viscosity. Am. J. Sci., 1893, 45, 87-96.

7 Hamrock, B. J. and Dowson, D. Ball bearing lubrication - the elastohydrodynamics of elliptical contacts, 1981 (Wiley-Interscience, New York).

8 Jacobson, B. O. Rheology and elastohydrodynamic lubrication. Tribology Series, vol. 19, 1991, pp. 1-381 (Elsevier, Amsterdam).

9 Höglund, E. Influence of lubricant properties on elastohydrodynamic lubrication. Wear, 1999, 232, 176-184.

10 Stähl, J. and Jacobson, B. A non-Newtonian model based on limiting shear stress and slip planes - parametric studies. Tribol. Int., 2003, 36, 801-806.

11 Bair, S. The high pressure rheology of some simple model hydrocarbons. Proc. IMechE, Part J: J. Engineering Tribology, 2002, 216(3), 139-149. DOI: 10.1243/135065 0021543960 .
12 Carreau, P. J. Rheological equations from molecular network theories. Trans. Soc. Rheol., 1972, 16(1), 99127.

13 Bair, S. A Reynolds-Ellis equation for line contacts with shear-thinning. Tribol. Int., 2006, 39, 310-316.

14 Bair, S., Vergne, P., and Querry, M. A. Unified shearthinning treatment of both film thickness and traction in EHD. Tribol. Lett., 2005, 18(2), 145-152.

15 Schmidt, A., Gold, P. W., Abmann, C., Dicke, H., and Loos, J. Viscosity-pressure-temperature behaviour of mineral and synthetic oils. J. Synth. Lubr., 2006, 18(1), 51-79.

16 Hamrock, B. J. Fundamentals of fluid film lubrication, 1994 (McGraw-Hill, New York).

17 Gohar, R. Elastohydrodynamics, 1988 (Ellys Horwood Ltd, John Wiley and Sons, London).

18 Hamrock, B. J. and Dowson, D. Isothermal elastohydrodynamic lubrication of point contacts. Part III - fully flooded results. J. Lubr. Technol., 1977, 99, 264-276.

19 Cheng, H. S. Calculations of elastohydrodynamic film thickness in high speed rolling and sliding contacts. Technical Report, MTI-67TR24, Mechanical Technology, Inc., 1967.

20 Gupta, P. K., Cheng, H. S., Forster, N. H., and Schrand, J. B. Viscoelastic effects in MIL-L-7808-type lubricant, part I: analytical formulation. Tribol. Trans., 1992, 35(2), 269-274.

21 Jubault, I., Molimard, J., Lubrecht, A. A., Mansot, J. L. and Vergne, P. In situ pressure and film thickness measurements in rolling/sliding lubricated point contacts. Tribol. Lett., 2003, 15, (4).

22 Bair, S. and Winer, W. O. A simple formula for EHD film thickness of non-Newtonian liquids. In Proceedings of the 23rd Leeds-Lyon Symposium, EHD-96, 1996, pp. 235-241 (Elsevier, Amsterdam).

23 Larsson, R. and Andersson, O. Lubricant thermal conductivity and heat capacity under high pressure. Proc. IMechE, Part J: J. Engineering Tribology, 2000, 214(4), 337-342. DOI: 10.1243/1350650001543223.

24 Johnson, K. L. and Tevaarwerk J. L. Shear behaviour of elastohydrodynamic oil films. Proc. R. Soc. London A, 1977, 356, 215-236.

\section{APPENDIX}

\section{Notation}

$a \quad$ hertz semi-width (radius) of the contact (m)

$b \quad$ transition radius from Newtonian to

non-Newtonian zone $(\mathrm{m})$

$E^{\prime}, E^{*} \quad$ Young's reduced modulus of two surfaces (Pa). $E^{\prime}=2 E^{*}$

$F_{\mu} \quad$ friction force $(N)$

$g_{\mathrm{V}}, g_{\mathrm{E}} \quad$ viscosity and elasticity parameters

$G \quad$ modulus of the lubricant $(\mathrm{Pa})$

$h_{\mathrm{c}} \quad$ non-Newtonian central film thickness (m)

$h_{\mathrm{Nc}} \quad$ Newtonian central film thickness (m)

$K \quad$ lubricant thermal conductivity $\left(\mathrm{W} / \mathrm{m}^{\circ} \mathrm{C}\right)$

$L \quad$ thermal loading factor

$m \quad$ dimensionless contact radius parameter 


$\begin{array}{llll}n & \text { power-law exponent } & \dot{\gamma} & \text { shear rate }\left(\mathrm{s}^{-1}\right) \\ p & \text { pressure (Pa) } & \Delta U & \text { sliding velocity (m/s) } \\ p_{0} & \text { Hertz (maximum) pressure (Pa) } & \zeta & \begin{array}{l}\text { limiting shear stress-pressure parameter } \\ \text { generalized viscosity (Pa s) }\end{array} \\ p^{*} & \text { transition pressure from Newtonian to } & \eta & \begin{array}{l}\text { low shear viscosity at atmospheric pressure } \\ \end{array} \\ r & \text { non-Newtonian zone (Pa) } & \eta_{0} & \text { (Pa s) } \\ R & \text { contact radius }(\mathrm{m}) & & \text { film thickness parameter } \\ \mathrm{SRR} & \text { reduced radius of curvature (m) } & \lambda & \text { friction coefficient } \\ T & \text { slide-roll ratio (per cent) } & \mu & \text { surface roughness }(\mathrm{m}) \\ U & \text { bulk temperature }\left({ }^{\circ} \mathrm{C}\right) & \sigma & \text { shear stress }(\mathrm{Pa}) \\ W & \text { rolling velocity }(\mathrm{m} / \mathrm{s}) & \tau & \text { limiting shear stress }(\mathrm{Pa}) \\ & \text { contact load }(N) & \tau_{\mathrm{L}} & \text { limiting shear stress at atmospheric } \\ \alpha & \text { pressure-viscosity coefficient }\left(\mathrm{Pa}^{-1}\right) & \tau_{0} & \text { pressure }(\mathrm{Pa}) \\ \beta & \text { temperature-viscosity coefficient }\left(\mathrm{K}^{-1}\right) & \varphi_{\mathrm{T}} & \text { thermal film thickness reduction factor }\end{array}$

